\title{
A Cross-sectional study among Hospital Employees- Metabolic Syndrome and Shift Work
}

\author{
Santhosh E Kumar'1, Antonisamy. B ${ }^{2}$, Henry Kirupakaran ${ }^{3}$, Reginald G Alex ${ }^{4}$ \\ ${ }^{1}$ Departments of Hepatology, Christian Medical College \\ ${ }^{2}$ Biostatistics, Christian Medical College \\ ${ }^{3}$ Staff student Health Services, Christian Medical College \\ ${ }^{4}$ General Medicine, Christian Medical College \\ Ida Scudder Road,Vellore, Tamil Nadu 632004, India
}

\begin{abstract}
Introduction: Shift workers and metabolic syndrome are on the rise in developing nations. The link between Metabolic syndrome and shiftwork is not clear. This study aims to measure the prevalence of metabolic syndrome among shift workers and daytime workers and to assess the association between metabolic syndrome and shift work. Methods: Crosssectional study was done in a South Indian hospital. Participants were selected via systematic random sampling between the age group of 25 -50 years. There were two study groups - day and shift workers. Sample size calculation was done with an alpha error of 0.05 and power of $80 \%$ to detect a $12.5 \%$ difference for metabolic syndrome prevalence between the two groups. Outcomes studied include the prevalence of metabolic syndrome and odds of developing metabolic syndrome among shift workers. The Chi-square test and independent t-test were the tests of significance used. The impact of relevant parameters on metabolic syndrome was assessed using univariate and multivariable analysis. Results: Eighty employees were studied in each group. At baseline, differences include; daytime workers were older in age, had a better quality of sleep, were less active physically, and consisted of more vegetarians. The prevalence of metabolic syndrome prevalence was thirty-three percent among the participants. The odds ratio (adjusted for relevant confounders) for shift workers to develop metabolic syndrome was 0.55 (95\% CI 0.24 -1.29). Conclusion: Metabolic syndrome was diagnosed in a third of the hospital employees studied. There was no statistical difference between shift and daytime workers for the prevalence of metabolic syndrome. Increased awareness, screening, and preventive measures of the disease are recommended.
\end{abstract}

Keywords: daytime, hospital, metabolic syndrome, shift work, sleep

\section{Corresponding Author:}

Santhosh E Kumar

Email: santhoshkumare@gmail.com

Phone: +91-9655505244

\section{INTRODUCTION}

Scientific advancement has led to change in the facilities, trends of human behavior, lifestyle, and also a spectrum of new diseases. Medicine has seen the shift of burden from infectious diseases to non-communicable diseases. Breadwinners in developing countries have traditionally been farmers; however, with the industrial boom, there is a rise in the population of Indians in the industrial sector (Mehta, 2016). To increase production and output, the concept of shift work has now become a global norm, and up to twenty percent of workers in the European Union and the United States are shift workers (Messenger," 2018). Multiple metabolic diseases are implicated to be increased among shift workers recently. The nature of diseases is varied obesity, hypertension, diabetes, and cardiovascular diseases (Wang et al., 2011). Shift work perturbs the circadian rhythm and leads to adverse health effects, and causes metabolic diseases (Maury et al., 2010) (Zhao and Turner, 2008). A systematic review of 10 studies showed varied results. The majority of the studies were in favor of increased risk among shift workers for diseases. The criticism for these studies was that confounding factors, including sleep, were not taken into consideration. The studies that accounted for sleep and other confounding factors showed no statistically increased risk among the shift workers (Canuto et al., 2013). The prevalence of metabolic syndrome has been increasing worldwide, and it is known to precede cardiovascular events. The prevalence of Metabolic syndrome among Indians was 41\% (Khan et al., 2018). Does change in the circadian rhythm and sleep disruption cause metabolic syndrome? Or does the human body accommodate over time, and there are few ill effects? These questions are not answered. Hitherto this issue had not been studied in the Indian population, where the prevalence of 
shift workers and metabolic syndrome is increasing. The study was conducted among hospital employees and to understand metabolic syndrome prevalence in this group and to assess for association (if any) with shift work.

\section{METHODS}

This study was done in a tertiary care hospital in India. The hospital had over 8000 staff members. Participants in the study were staff members of the ages between twenty-five and fifty years, who served a minimum of five years in shift work or daytime work. Pregnant women were excluded. The shift working group consisted of hospital attendants doing shifts, laboratory technicians, radiology technicians, critical care therapists, and pharmacists. The daytime group consisted of hospital attendants doing only daytime work, secretaries, librarians, accounting staff, physiotherapists, and medical records staff. Doctors were not included as they neither fitted into typical daytime nor rotating shift work. Nurses were excluded as the hospital nursing administration refused willingness to participate. Sample size calculation was done with an alpha error of 0.05 and power of study of $80 \%$, for $12.5 \%$ increased prevalence of metabolic syndrome among shift workers, 158 participants (79 in each group) was needed to be studied (Ye et al., 2013). The total hospital employees' list was obtained from the hospital administration, and participants fulfilling study criteria were shortlisted. A systematic random sampling method was used for the selection of study participants (Figure 1). The study was approved by Institutional Review Board and Ethics Committee. All the participants have consented to their participation.

This study was done from August 2014 to April 2015. The study is funded by the hospital's research grant. However, there was no interference by the management of the hospital with regard to data collection or analysis.

Weight measurement was done using a calibrated weighing machine with the participant wearing his/her clothes and no footwear. Height was measured using a stadiometer, with the patient not wearing footwear and their back and head in contact with the wall. The waist measurement was taken midway between the costal margin and the iliac crest, with the patient standing, using an

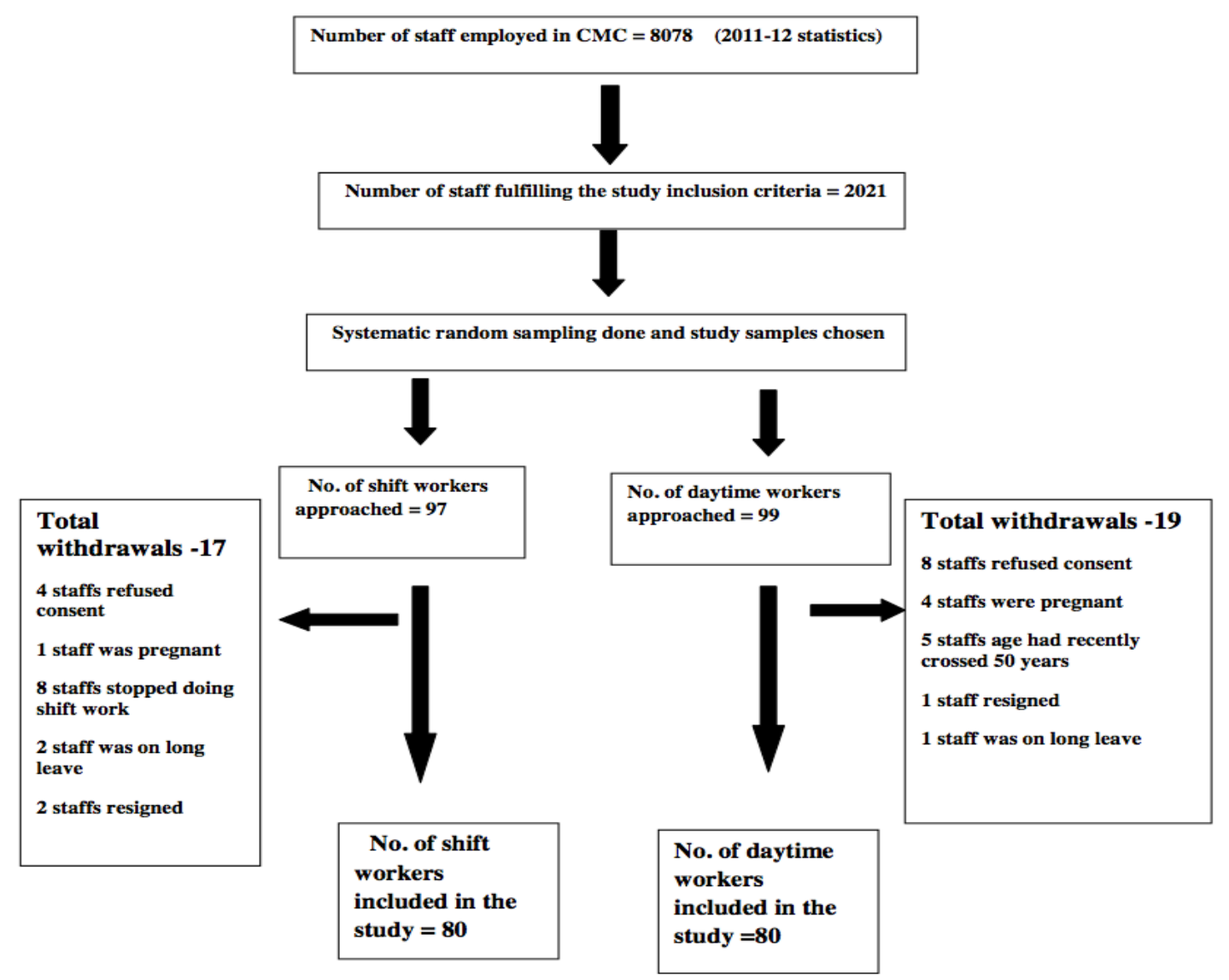

Figure 1. A Study Flow Chart 
inch tape measure with a one-millimeter division. Blood pressure was measured after ten minutes of interaction using a non-mercury sphygmomanometer with the participant being seated and arm rested on the table. The palpatory method for estimation of systolic blood pressure was used prior to the auscultatory method for recording accurate systolic and diastolic blood pressure readings. Pre-validated questionnaires were used for measuring qualitative variables; GPPAQ -General practice physical activity questionnaire for measuring the physical activity (Ahmad et al., 2015), perceived stress scale (PSS) for assessment of the level of stress (Andreou et al., 2011), and PSQI- Pittsburgh sleep quality index for measuring the quality of sleep (Spira et al., 2012). Required samples for blood tests were collected from the participants after eight hours of overnight fast between $7 \mathrm{AM}$ and $10 \mathrm{AM}$. For shifting working group members, their blood was collected when they performed either day or evening duty.

International Diabetic Federation (IDF) definition of Metabolic syndrome (2005) was used in our study. As per the definition, "metabolic syndrome was defined if a person had central obesity (waist circumference $\geq 90 \mathrm{cms}$ for males and $\geq 80 \mathrm{cms}$ for females, or if BMI was above $30 \mathrm{~kg} /$ meters) along with two out of the following four features: elevated blood pressure $(\geq 130 \mathrm{mmHg}$ of systolic pressure or $\geq 85 \mathrm{mmHg}$ of diastolic pressure or treatment for hypertension), elevated triglycerides ( $>150 \mathrm{mg} /$ $\mathrm{dl}$ or already on treatment for this abnormality), elevated fasting glucose $(\geq 100 \mathrm{mg} / \mathrm{dl}$ or diabetic on treatment), decreased HDL cholesterol $(<40$ $\mathrm{mg} / \mathrm{dl}$ in males and $<50 \mathrm{mg} / \mathrm{dl}$ in females or on treatment for this abnormality)" (Alberti et al., 2006). Hypertension was defined according to Joint National Committee (JNC) 7 recommendations ( $\geq 140 / 90 \mathrm{mmHg}$ ) (Chobanian et al., 2003). Diabetes mellitus was defined if fasting glucose was $\geq 126 \mathrm{mg} /$ $\mathrm{dl}$ and/or postprandial 2 hours glucose $\geq 200 \mathrm{mg} / \mathrm{dl}$ and/or $\mathrm{HbA} 1 \mathrm{C} \geq 6.5 \mathrm{gm} \%$. Obesity was defined as per Asian cut-off of BMI $\geq 25 \mathrm{~kg} /$ meters square (World Health Organization, 2000).

The primary outcome of our study was to detect the prevalence of metabolic syndrome among the participants. Secondary outcomes include; calculation of the odds ratio for developing metabolic diseases among the shift workers such as metabolic syndrome, hypertension, obesity, central obesity, decreased HDL cholesterol, impaired fasting glucose, and elevated triglycerides.
Epidata version 3.1 was used to enter the data. Stata software version 13 was used for data analysis. The data had a normal distribution. Categorical variables were summarized as count and percentage. Continuous variables were presented as mean and standard deviation.

Chi-square test and t-test were used to examine the difference in the proportion of baseline categorical and mean difference in continuous

variables between the shift and daytime workers, respectively. Univariate analysis and multivariable logistic regression were used to determine the independent effect shift work had on metabolic syndrome and other outcomes, simultaneously adjusting for predictor variables. The impacts of each of these factors were reported using an odds ratio and $95 \%$ confidence interval, and a $\mathrm{P}$-value of 0.05 .

\section{RESULTS}

Using systematic random sampling, participants were chosen, 99 in the daytime workers and 97 in the shift workers. The number of patients excluded and the reasons for exclusion are mentioned in figure 1. Finally, 80 participants in each of the groups were studied and analyzed. Baseline characteristics are presented in Table 1.

The mean age of the participants was 38.2 years ( \pm 7.02 years), with the shift workers being significantly younger $(\mathrm{P}<0.001) 35.2$ years $(\mathrm{SD} \pm 6.2$ years) compared to the daytime workers' 41.2 years ( $\mathrm{SD} \pm 6.5$ years). The study population consisted of more males, $92(57.5 \%)$, and the sex distribution was the same between the shift and daytime workers. The designation of staff members was different between the shift and daytime workers for all cadres except attendants, who were equally distributed between the two groups. The daytime group consisted of more office staff. All the pharmacists were performing shift work. There was more technical staff in the shift group $27(33.7 \%)$ compared to the daytime group $18(18.8 \%)$. The use of tobacco and alcohol consumption was noted more in the shift working group. Concerning the timing of the meal and junk food eating, there was no difference between the two groups. The daytime group had more vegetarians, $16(20 \%)$ compared to the shift workers, $6(7.5 \%)$. The number of participants with known disease status of diabetes mellitus and systemic hypertension was not different between the two groups. However, the number of participants with known dyslipidemia 
Table 1. Baseline Characteristics of Shift and Daytime Workers in the Study of Metabolic Syndrome

\begin{tabular}{|c|c|c|c|c|}
\hline Parameter & $\begin{array}{c}\text { Total } \\
(\mathrm{N}=\mathbf{1 6 0})(\%)\end{array}$ & $\begin{array}{c}\text { Shift workers } \\
(\mathrm{N}=\mathbf{8 0})(\%)\end{array}$ & $\begin{array}{c}\text { Daytime workers }(\mathrm{N}=80) \\
(\%)\end{array}$ & P-value \\
\hline Age(years), Mean(SD) & $38.2(7.02)$ & $35.3(6.21)$ & $41.2(6.5)$ & $<0.001$ \\
\hline Male gender & $92(57.5)$ & $46(57.5)$ & $46(57.5)$ & 0.99 \\
\hline Designation Attendants & $57(35.6)$ & $29(36.2)$ & $28(35.0)$ & \multirow{4}{*}{$<0.001$} \\
\hline Technical staff & $42(26.2)$ & $27(33.8)$ & $15(18.8)$ & \\
\hline Office staff & $44(27.5)$ & $7(8.8)$ & $37(46.2)$ & \\
\hline Pharmacist & $17(10.6)$ & $17(21.2)$ & 0 & \\
\hline Smoker & $13(8.1)$ & $9(11.2)$ & $4(5.0)$ & 0.15 \\
\hline Alcohol Consumer & $25(15.6)$ & $15(18.7)$ & $10(12.5)$ & 0.28 \\
\hline Irregular food timing & $41(25.6)$ & $21(26.3)$ & $20(25)$ & 0.89 \\
\hline Frequent junk food eater & $94(58.8)$ & $54(67.5)$ & $40(50)$ & 0.18 \\
\hline Vegetarian & $22(13.8)$ & $6(7.5)$ & $16(20)$ & 0.02 \\
\hline Diabetes mellitus* & $11(6.9)$ & $3(3.8)$ & $8(10.1)$ & 0.11 \\
\hline Systemic hypertension $千$ & $22(13.8)$ & $9(11.3)$ & $13(16.5)$ & 0.34 \\
\hline Dyslipidemia & $16(10.1)$ & $4(5.0)$ & $12(15.2)$ & 0.03 \\
\hline \multicolumn{5}{|l|}{ Physical activity } \\
\hline Inactive & $34(21.3)$ & $7(8.8)$ & $27(33.8)$ & \multirow{4}{*}{0.001} \\
\hline Moderately inactive & $64(40.0)$ & $39(48.7)$ & $25(31.3)$ & \\
\hline Moderately active & $36(16.2)$ & $13(16.3)$ & $13(16.2)$ & \\
\hline Active & $36(22.5)$ & $21(26.2)$ & $15(18.7)$ & \\
\hline \multicolumn{5}{|l|}{ Stress $\S$} \\
\hline Much lower than average & $8(5.0)$ & $5(6.3)$ & $3(3.8)$ & \multirow{5}{*}{0.31} \\
\hline Slightly lower than average & $18(11.3)$ & $7(8.7)$ & $11(13.7)$ & \\
\hline Average & $38(23.7)$ & $15(18.7)$ & $23(28.8)$ & \\
\hline Slightly higher than average & $58(36.3)$ & $30(37.5)$ & $28(35)$ & \\
\hline Much higher than average & $38(23.7)$ & $23(28.8)$ & $15(18.7$ & \\
\hline Poor Sleep $\|$ & $71(44.4)$ & $42(52.5)$ & $29(36.2)$ & 0.04 \\
\hline BMI (kg/m2), Mean (SD) & $26.3(4.6)$ & $25.9(4.4)$ & $26.8(4.8)$ & 0.29 \\
\hline
\end{tabular}

*: Represents the participants who were known to have diabetes mellitus at the onset of the study

+ : Represents the participants who were known to have systemic hypertension at the onset of the study

\$:Physical activity was graded based on GPPAQ (General practice physical activity questionnaire)

$\S$ : Stress was scored based on PSS (Perceived stress scale)

II: Sleep was classified as good or bad based on PSQI (Pittsburgh sleep quality index)

was significantly higher (P 0.03) among the daytime workers $12(15.2 \%)$ compared to shift workers 4 $(5 \%)$.

The level of physical activity assessment showed that the shift working group was more physically active compared to the daytime working group (P 0.001). The levels of stress were not different between the two groups; however, the majority of the employees had reported slightly higher than average 58/160 (36.3\%) or much higher than average 38/160 (23.7\%) stress levels. The quality of sleep assessment had shown significantly better sleep (P 0.04) among the daytime workers. The mean body mass index (BMI) of the study group was $26.3 \mathrm{~kg} / \mathrm{m} 2( \pm 4.6 \mathrm{~kg} / \mathrm{m} 2)$. The BMI was not different between the two groups. Outcomes of the study are presented in Table 2.

The primary outcome, the prevalence of metabolic syndrome, was 53/160 (33.1\%) among the study participants. The prevalence of metabolic syndrome was $33 / 80(41.3 \%)$ among the day workers and 20/80 (25\%) among the shift working participants, and the difference was significant $(\mathrm{P}$ 0.03 ). The odds ratio of the shift workers to develop 
Table 2. Primary Outcome and Secondary Outcomes of the Study on Shift Work and Metabolic Syndrome among Hospital Employees

\begin{tabular}{|c|c|c|c|c|c|c|c|}
\hline Outcome & 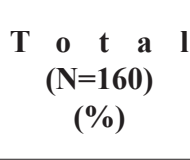 & $\begin{array}{c}\mathbf{S} \underset{\text { h }}{\mathbf{f}} \mathbf{t} \\
\text { Workers } \\
(\mathrm{N}=\mathbf{8 0})(\%)\end{array}$ & $\begin{array}{c}\text { D a y t i m e } \\
\text { Workers } \\
(\mathbf{N}=80) \\
(\%)\end{array}$ & $\begin{array}{c}\text { Unadjusted } \\
\text { Odd's Ratio } \\
(95 \% \mathrm{CI}) \\
\text { (shift workers) }\end{array}$ & P-value & $\begin{array}{c}\text { Adjusted } \\
\text { Odds Ratio } \\
\text { (95\% CI) } \\
\text { (shift workers) }\end{array}$ & P-value \\
\hline \multicolumn{8}{|l|}{$\begin{array}{l}\text { Primary } \\
\text { Outcome }\end{array}$} \\
\hline $\begin{array}{l}\text { Metabolic } \\
\text { syndrome }\end{array}$ & $53(33.1)$ & $20(25.0)$ & $33(41.3)$ & $0.47(0.24-0.93)$ & 0.03 & $0.55(0.24-1.29)$ & 0.17 \\
\hline \multicolumn{8}{|l|}{$\begin{array}{l}\text { Secondary } \\
\text { Outcomes }\end{array}$} \\
\hline $\begin{array}{l}\text { Systemic } \\
\text { Hypertension }\end{array}$ & $35(21.8)$ & $16(20.0)$ & $19(23.8)$ & $0.8(0.4-1.7)$ & 0.56 & $1.08(0.4-2.9)$ & 0.88 \\
\hline $\begin{array}{l}\text { Impaired } \\
\text { Fasting } \\
\text { glucose }\end{array}$ & $36(22.5)$ & $11(13.8)$ & $25(31.3)$ & $0.35(0.16-0.77)$ & 0.01 & $0.58(0.21-1.58)$ & 0.29 \\
\hline $\begin{array}{l}\text { Central } \\
\text { Obesity }\end{array}$ & $104(65)$ & $49(61.3)$ & $55(68.8)$ & $0.72(0.37-1.38)$ & 0.32 & $0.68(0.27-1.67)$ & 0.39 \\
\hline Obesity & $101(63.1)$ & $49(61.3)$ & $52(65.0)$ & $0.93(0.48-1.79)$ & 0.8 & $0.98(0.4-2.2)$ & 0.96 \\
\hline $\begin{array}{l}\text { Elevated } \\
\text { triglycerides }\end{array}$ & $43(26.9)$ & $23(28.8)$ & $20(25.0)$ & $1.21(0.6-2.4)$ & 0.59 & $0.95(0.35-2.6)$ & 0.93 \\
\hline $\begin{array}{l}\text { Decreased } \\
\text { HDL }\end{array}$ & $95(61.7)$ & $47(58.8)$ & $48(60.0)$ & $0.95(0.51-1.78)$ & 0.87 & $0.66(0.27-1.58)$ & 0.35 \\
\hline $\begin{array}{l}\text { Diabetes } \\
\text { mellitus }\end{array}$ & $20(12.5)$ & $8(10.0)$ & $12(15.0)$ & $0.63(0.24-1.63)$ & 0.34 & $1.12(0.3-4.1)$ & 0.87 \\
\hline
\end{tabular}

* Odd's Ratio is adjusted for age, gender, diet, physical activity, sleep, stress, and alcohol consumption

metabolic syndrome was 0.47 (95\% CI; $0.24-0.93)$. We had performed univariate analysis and multiple logistic regression for factors that had a significant effect on univariate analysis, and the odds ratio after adjusting the covariates was $0.55(95 \% \mathrm{CI} ; 0.24$ -1.29; P 0.17).

The daytime workers had an increased mean age of 5.98 years. Increasing age had an association with the development of metabolic syndrome on univariate analysis the odds ratio 1.05 (95\% CI;1.002-1.10; P 0.04). However, on multiple logistic regression, this finding was not statistically significant, the odds ratio 1.04 (95\% CI;0.981.10 , P 0.21). Lifestyle variables such as smoking, alcohol consumption, non-vegetarian diet, junk food consumption, sleep, physical activity, and stress levels were not showing significant correlation on multivariate analysis for the development of the metabolic syndrome. Timing of food, however, showed that eating meals at the regular time was protective against metabolic syndrome with the odds ratio of 0.3 (95\% CI; 0.1-0.93, P 0.04). The number of night shifts per month in this study by the shift workers was as follows; $<5(33.3 \%), 6-10(54.3 \%)$, and $>10(12.4 \%)$. On analyzing for the association for risk of metabolic syndrome with increasing night duty, there was no difference $(\mathrm{P}=0.82)$.

The newly diagnosed impaired fasting glucose in the study was $36 / 160(22.5 \%)$ among the study population and $11 / 80(13.8 \%)$ among the shift workers, and 25/80 (31.3\%) among the daytime workers (P 0.01) with an odds ratio of $0.35(95 \%$ CI; $0.16-0.77)$. The odds ratio after adjusting for the covariates was 0.58 (95\% CI; 0.21-1.58; P 0.88). Prevalence of systemic hypertension, central obesity, obesity, elevated triglycerides, and decreased HDL was not statistically different between the shift and daytime workers.

\section{DISCUSSION}

The prevalence of metabolic syndrome that was seen in our study was comparable to another study from urban India (33.5\%) and also with population study done among adults in the United States of America (34.5\%) (Prasad et al., 2012; Ford, 2005). Our study findings were suggesting more metabolic syndrome among the daytime workers $(41.3 \%)$ compared to shift workers $(25 \%)$. However, there were important baseline characteristics that were 
different between the shift working and daytime working groups, including age (shift workers were younger), physical activity (shift workers were more active), sleep (quality of sleep was poorer among the shift workers), and diet (shift workers had more non-vegetarians). Therefore, multiple logistic regression was done, and the odds ratio for metabolic syndrome among shift workers thus calculated was not statistically significant.

In the analysis to understand if there was any lifestyle factor that was associated with metabolic syndrome, it was found that having meals at a regular time was protective. However, other important factors such as sleep, physical activity, stress, junk food, smoking, and alcohol did not show any association.

Other secondary outcome parameters such as hypertension (newly diagnosed), central obesity, obesity, hypertriglyceridemia, and elevated HDL were not different between the shift workers and daytime workers. Impaired fasting glucose was more among the daytime workers; however, this was not statistically significant after multiple logistic regression. These findings are keeping in with the understanding that these metabolic diseases have multiple risk factors (genetic, environmental, and lifestyle) and thereby difficult to assign the doseresponse relationship to one particular risk factor (Gosadi, 2016) (Ahmad and Ahluwalia, 2019).

There is evidence to suggest clockwise rotation of the shifts had fewer health hazards compared to anticlockwise rotation or no fixed rotation, and all the shift workers in the study had clockwise rotation of shifts (Pati, Parganiha, and Reinberg, 2001). An increasing number of night shifts per month was shown to affect health adversely (Pati, Parganiha, and Reinberg, 2001; Wang et al., 2014). In this study, increased night duties were also not associated with the development of the metabolic syndrome. The above could be few reasons why the shift workers in our study had better health parameters than expected.

The other possibility to consider to explain our results is the 'reverse causation hypothesis' (Gerstman, 2013). As per reverse causation theory, employees who had health ailments preferred to do daytime work, while the healthy did shift work.

The strengths of this study were; we studied a common problem affecting one-third of the Indian population; therefore, it is relevant. We are not aware of a similar study being done among Indian hospital employees. This study had other positives like studying lifestyle factors such as sleep, physical activity, stress, and diet, which are known impactors of non-communicable diseases such as metabolic syndrome. This study had limitations, such as studying participants that were unequally distributed between the two groups in terms of their age and designation. Nurses being a predominant proportion of the workforce who were not part of the study is also one of the drawbacks of this study. The study results may or may not apply to the general public as the study participants were hospital employees; therefore, presumably, they might have better health awareness and practices. Another limitation of this study was that this is cross-sectional in design, and a multi-center large prospective study may provide additional information on the incidence of metabolic syndrome and complications among participants.

Based on our study, the authors conclude that in countries such as India with a strikingly high prevalence of metabolic syndrome, there has to be increased awareness among the population, increased health screening by the health authorities. Regular meal timing had a protective impact against metabolic syndrome in this study, and the workplace could permit its employees to have meals at regular times daily. The promotion of physical activity in the workplace by administrators could be beneficial. Stress levels are higher than average for the majority of the participants among hospital employees in this study, and the administration of various institutions need to be cognizant of this and should screen their employees and consider measures to de-stress. For shift workers, the authors recommend that they should have a clockwise rotation of shifts with night shift duration not exceeding one week in a month, as it was shown to be safe in this study. For future studies, the authors suggest that a large multicenter prospective cohort study be conducted in a homogenous population with appropriate matching for age.

\section{CONCLUSION}

The prevalence of metabolic syndrome among hospital employees studied in an Indian setting was $33.1 \%$. There was no difference in the prevalence of metabolic syndrome between shift and daytime workers in this study. It is advisable to increase awareness and health screening among employees. Regular meal timing and physical activity need to be promoted in the workplace. Large multi-center prospective cohort studies are needed to validate these findings. 


\section{ACKNOWLEDGEMENT}

The authors thank the Christian Medical College, Vellore (CMC) hospital administration for permitting us to study the employees and also for funding the study and are grateful to all the participants. The authors extend our gratitude to the General Medicine department of CMC, Vellore for their valuable suggestions and support.

\section{REFERENCES}

Ahmad, S., Ahluwalia, T.S., 2019. Editorial: The Role of Genetic and Lifestyle Factors in Metabolic Diseases. Frontiers in Endocrinology 10(July), pp. 475-478.

Ahmad, S. et al. (2015) 'Evaluation of reliability and validity of the General Practice Physical Activity Questionnaire (GPPAQ) in 60-74 year old primary care patients', BMC Family Practice, 16(1), pp. 113-122.

Alberti, K. G. M. M., Zimmet, P. and Shaw, J. (2006) 'Metabolic syndrome--a new worldwide definition. A Consensus Statement from the International Diabetes Federation', Diabetic Medicine: A Journal of the British Diabetic Association, 23(5), pp. 469-480.

Andreou, E. et al. (2011) 'Perceived Stress Scale: Reliability and Validity Study in Greece', International Journal of Environmental Research and Public Health, 8(8), pp. 3287-3298.

Canuto, R., Garcez, A. S. and Olinto, M. T. A. (2013) 'Metabolic Syndrome and Shift Work: A Systematic Review', Sleep Medicine Reviews, 17(6), pp. 425-431.

Chobanian, A. V. et al. (2003) 'The Seventh Report of the Joint National Committee on Prevention, Detection, Evaluation, and Treatment of High Blood Pressure: the JNC 7 report', JAMA, 289(19), pp. 2560-2572.

Ford, E. S. (2005) 'Prevalence of the Metabolic Syndrome Defined by the International Diabetes Federation among adults in the U.S', Diabetes Care, 28(11), pp. 2745-2749.

Gerstman , B. B. (2013) Epidemiology Kept Simple: An Introduction to Traditional and Modern Epidemiology, 3rd Edition. West Sussesx: John Wiley \& Sons.

Gosadi, I.M., (2016) 'Assessment of the Environmental and Genetic Factors Influencing Prevalence of Metabolic Syndrome in Saudi Arabia', Saudi Medical Journal, 37(1),pp. 12-20.
Khan, Y., et. al., (2018) Prevalence of Metabolic Syndrome Crossing 40\% in Northern India: Time to act fast before it runs out of proportions. Jounal of Family Medicine and Primary Care, 7(1), 118-123.

Maury, E., Ramsey, K. M. and Bass, J. (2010) 'Circadian Rhythms and Metabolic Syndrome: from Experimental Genetics to Human Disease', Circulation Research, 106(3), p. 447.-462

Mehta, S., 2016. Innovation and Employment: A Study of Indian Manufacturing Sector. Millennial Asia 7(2), 184-206.

Messenger, J (2018) Working Time and the Future of Work. Geneva: International Labour Organization.

Pati, A.K., Parganiha, A. and Reinberg, A., 2001. 'Shift Work: Consequences and Management', Current Science, 81(1), pp. 32-52.

Prasad, D.S., et. al. (2012) 'Prevalence and Risk Factors for Metabolic Syndrome in Asian Indians: A community Study from Urban Eastern India', Journal of Cardiovascular Disease Research, 3(3), 204-211.

Spira, A. P. et al. (2012) 'Reliability and Validity of the Pittsburgh Sleep Quality Index and the Epworth Sleepiness Scale in Older Men', The Journals of Gerontology: Series A Biological Sciences and Medical Sciences, 67)4, pp. 433-439

Wang, F., et. al. (2014) Meta-analysis on Night hift Work and Risk of Metabolic Syndrome. Obesity Reviews 15(9), pp.709-720.

Wang, X.-S., et. al. (2011) Shift Work and Chronic Disease: The Epidemiological Evidence. Occupational Medicine (Lond), 61(2),pp. 78-89.

World Health Organization (2000) The AsiaPacific Perspective : Redefining Obesity and its Treatment. Sydney: Health Communications Australia.

Ye, H. H. et. al. (2013) 'The Association between Shift Work and the Metabolic Syndrome in Female Workers', Annals of Occupational and Environmental Medicine., 25(33), pp. 1-8.

Zhao, I., and Turner, C.(2008) 'The Impact of Shift Work on People's Daily Health Habits and Adverse Health Outcomes', Australian Journal of Advanced Nursing, 25(3), pp.8-22 